Running head: AGE AND HEALTH EFFECTS ON SENTENCING DECISIONS

Effects of Offenders’ Age and Health on Sentencing Decisions

Katrin Mueller-Johnson and Mandeep K. Dhami

University of Cambridge, UK

Send correspondence to:

Katrin Mueller-Johnson

Institute of Criminology

University of Cambridge

Sidgwick Avenue

Cambridge

CB39DA, UK

E-mail: kum20@cam.ac.uk

Tel: +44 (0) 1223767184

Fax: +44 (0) 1223335356 


\begin{abstract}
Two experiments investigated the effects of age and health on mock judges' sentencing decisions. The effects of these variables on length of prison sentence were examined in the context of offence severity and prior convictions. Experiment 1 involved a violent crime. Main effects were observed for age, health, offence severity and prior convictions. There was also an age by offence severity interaction. Experiment 2 involved a child sexual abuse case. Main effects were observed for health, offence severity and prior convictions. In addition, an age by offence severity by prior convictions interaction effect was found. Thus, across both experiments, the age leniency effect was moderated by legal factors, suggesting that extra-legal factors affect sentencing in the context of legal factors. Further, for both offences, offenders in poor health received shorter sentences than offenders in good health, suggesting that health deserves further research attention as an extra-legal variable.
\end{abstract}

Key words:

Psychology and Law, Sentencing, mock-jury decisions, defendant, age, health 
Sentencing is often geared toward simultaneously achieving multiple aims, protection of the public, punishment of offenders, reduction of crime, rehabilitation of offenders, and victim reparation. Prison sentences, in particular, may be justified on grounds which are intended to satisfy several of these aims, which in legal parlance would include incapacitation, desert or retribution, deterrence and rehabilitation (von Hirsch \& Ashworth, 1998). Although the factors that ought to guide sentencing decisions are outlined in many jurisdictions (e.g., sentencing guidelines often specify offence severity and prior convictions as legally relevant variables), research suggests that sentencers may rely on a host of extra-legal factors (for a brief review see, Dhami, 2007). In this paper, we focus on the effect of offender age and health in the context of offence severity and prior convictions. The effect of age of offender is relatively under explored in sentencing research since offenders’ age has typically been ignored, controlled or held constant. Furthermore, the effect of offender health on sentencing has not yet been investigated. In fact, few studies examining the effect of age have considered it in the context of legal factors. Beyond the distinction between youth (those aged under 21) and adult offenders (those aged over 21), age is not considered to be a factor relevant to sentencing. Nevertheless, there are theoretical reasons to expect that older offenders (aged 60 or older) might be given more lenient sentences: For instance focal concerns theory (Steffensmeier, Ulmer, \& Kramer, 1998) suggests that legal decision makers take three main (focal) concerns into account when reaching sentencing decisions: offender blameworthiness, protection of the community, and practical constraints and consequences. We argue that although older offenders may not differ by virtue of their age from younger offenders in their perceived blameworthiness, the need to protect the 
community from them may be lower, and the practical constraints and consequences of prison sentences may be higher, such that shorter prison sentences are imposed.

Offender blameworthiness covers factors like offence severity, prior criminal record, or previous victimisation. Age may be considered a factor mitigating blameworthiness where the offender is a child or youth, but once mature adulthood is reached age in itself should not constitute a factor affecting blameworthiness. The need to protect the community from older offenders may not be as important because they have a lower probability of recidivism than younger offenders (Farrington, 1986). Older offenders may also be considered to be “incapacitated by nature” due to their frailty and poor health. The practical constraints and consequences of prison sentences at the organisational level may also be greater for older offenders than their younger counterparts because the prison service is not well equipped to deal with older offenders (Aday, 2003). Older offenders may have chronic health problems that prisons do not have provisions to fully address; in addition, mobility issues may arise as prison cells and facilities are not equipped for frail elderly. Prison activities also typically cater for younger adults in need of training (e.g. education and work programmes). Furthermore, at the individual level, if prison caters less well for elderly prisoners such sentences may impact more severely on older offenders. Therefore, the above considerations could lead a sentencer to impose shorter sentences for older offenders compared to their younger counterparts.

Clearly, part of the issue concerning the age leniency effect in the sentencing of older offenders may be physical health. In fact, physical ill-health and old age may be confounded, as generally, older adults, and research shows this to be even more so for older offenders (Aday, 2006), may be in poorer health than their younger counterparts. It is thus possible that part of the age leniency effect may be due to ill health, rather than the age of an offender. 
In the present paper, we report the results of two experiments designed to examine the age leniency effect in the context of other relevant factors such as an offender's health, prior convictions, and offence severity. Experiment 1 investigates the effect of these factors in the context of a violent crime; a crime type for which the age leniency effect has been demonstrated before but never been examined together with offender health. Experiment 2 extends this investigation to child sexual abuse where age leniency has not yet been studied but where, given the higher average age of offenders for this crime and the increase of child sexual abuse prosecutions of older offenders for crimes that happened long ago, it may be particularly pertinent to study the age leniency effect.

\section{Age Effects on Sentencing}

Research that has examined the effects of age on sentencing has largely used archival analysis or analysis of sentencing statistics. However, archival research is problematic because age may be confounded with other factors such as offence severity and previous convictions thus making it difficult to determine the independent effects of age on sentencing. Alternatively, a few experimental studies have systematically varied offender age, while keeping other factors constant. However, these experimental studies have not examined how legal factors may moderate the effect of age. We review the findings of these studies below.

\section{Studies Based on Archival Data or Sentencing Statistics}

Studies investigating the age leniency effect in sentencing can broadly be distinguished as using one of two methodologies, either based on a content analysis of samples of court records 
as primary data or, where detailed sentencing statistics are routinely available, based on secondary data analyses on the whole population of sentenced offenders. Studies using either methodology have so far demonstrated age leniency effects for old age (for the approach using court records see e.g. Champion, 1987, Champion, 1988, Johnson \& Alozie, 2001, Turner \& Champion, 1989; for studies using sentencing statistics, see Steffensmeier et al, 1995, Steffensmeier et al, 1995, Steffensmeier \& Motivans, 2000, Wilbanks, 1988).

Wilbanks (1988) originally examined age differences for all felony cases that were processed by the police, prosecution and courts in California in 1980. He found that older offenders (i.e. 60 years and older) were less likely to be sentenced as felons and less likely to receive prison or jail sentences than younger offenders (i.e. those aged 20 to 59 years). The difference persisted across different offence types, although it was larger for some types (e.g. for robbery) than for others (e.g. fraud). Similarly, Turner and Champion (1989) examined cases sentenced in Kentucky, Tennessee, and Virginia between 1970 and 1984 and found a leniency effect for older offenders. For robbery offences, older offenders (i.e. 60 years and over) were more likely to be placed on probation than younger offenders (i.e. under 60 years). If imprisoned, these older offenders received, on average, a shorter sentence than younger offenders. This effect persisted after the sample was separated into those without a prior criminal record and those with at least one previous conviction. However, neither of these early studies controlled for the potentially confounding effects of, for instance, offence severity, (and unlike Turner and Champion [1989], Wilbanks [1988] did not control for prior convictions).

More recent archival studies have made greater efforts to disentangle the effects of age from other factors. Age leniency effects have been shown for older offenders at both the US state- and federal levels (Champion, 1988; Johnston \& Alozie, 2001; Steffensmeier et al., 1995; 
Steffensmeier \& Motivans, 2000). Interestingly, they have also been shown for jurisdictions that use sentencing guidelines (e.g. Steffensmeier et al., 1995), despite the fact that according to the guidelines age is not a factor to be taken into consideration: For instance, Steffensmeier et al. (1995) examined Pennsylvania state sentencing data from 1989 to 1990 and found that while in accordance with other studies offence severity and prior criminal record had a large effect on the decision to imprison and sentence length, there also were age effects. Firstly, offenders aged between 20 and 29 years had the largest odds of imprisonment, while offenders over 60 years had the smallest odds. This age leniency effect for older offenders was observed across offence types, with the effect being greatest for violent offences, followed by property offences, and smallest for drug offences. Within the category of violent offences the age leniency effect was particularly pronounced for homicide and robbery. Second, offenders aged between 20 and 29 received the longest sentences, while those aged over 60 years received the shortest sentences. Overall, offenders over 60 years received sentences that were nearly 9 months shorter than those received by comparable offenders aged 30 to 39 years. These findings were replicated by Steffensmeier and Motivans (2000). On the federal sentencing level, Champion (1988) investigated the judgments (with and without plea-bargaining) of 120 federal judges from six circuits. It was found that for all offences, older offenders (i.e. aged over 60) received more lenient sentences than younger offenders (i.e. under 60 years). When differentiating between offence types, older offenders received more lenient sentences for both violent and property offences than younger offenders. For property offences, older offenders' sentences were nearly three times less severe than younger offenders' sentences. Experimental Studies 
In contrast to prior experimental research on sentencing that has examined the effect of defendant age within a narrow range (e.g., Kapardis \& Farrington, 1981, where the defendant was aged 22 or 32), the first experimental study of age effects on sentencing that included older offenders of pensionable age was Silverman et al. (1984), where age of the defendant was varied to be 20, 40 or 60 years. Here mock judges, asked to sentence the defendant for a crime of theft, chose one of five punishment options that could be ranked on a scale of severity from no punishment, strong warning, probation, less than one year in jail, and more than one year in jail. It was found that both the 20 year-old and the 60 year-old were sentenced more leniently than the 40 year-old in that the youngest and oldest age groups were more likely to receive a sentence that kept them out of prison than the 40 year-old offender age group. Recently, Bergeron and McKelvie (2004) varied both offender age (i.e., 20, 40, or 60 years) as well as offence type (i.e., murder or theft). Although in contrast to Silverman et al.’s (1984) study, an age effect was not found for theft, it was observed for murder. Furthermore, consistent with the earlier study, the 20 and 60 year-old offenders were treated more leniently than the 40 year-old offender. The leniency effect was most pronounced for the 60 year-old offender (see McKelvie \& Bergeron [2003] for additional analyses of the Bergeron \& McKelvie [2004] data). However, in two other experimental studies of sentencing for violent assault (Higgins, Heath, \& Grannemann, 2007; Loeffler \& Lawson, 2002), no leniency effect was found for the older offender (i.e. 65 years; 60 years respectively), who received the same length of sentence as the younger offender (i.e. 22 years; 25 years respectively). Overall, the experimental studies to date indicate that the relationships between age and sentence severity may be curvilinear.

While the experimental studies overcome some of the limitations of archival research, the former are often limited in scope. Indeed, previous experimental research looking at the effects 
of age has not typically included legally relevant factors. Thus, it is possible that the importance of age in sentencing decisions may have been overemphasised. In fact, it is also currently unknown if age interacts with legal factors such as offence severity, and prior convictions. Health as a Mitigating Factor

One potential explanation for the age leniency effect concerns the physical health of the offender. There is evidence suggesting that older offenders often have poorer physical health. For instance, compared to their younger counterparts, older prisoners suffer more frequently from chronic illness, require frequent medication and special diets, which makes it difficult for them to adapt to imprisonment as well as making it difficult to manage them in prison (Aday, 2003). It has been argued that therefore older prisoners in poor health may feel the "pains of imprisonment” more keenly than younger offenders (Kerbs, 2000) and that a prison sentence can have a greater impact on them more than on younger, healthy, offenders (Ashworth, 2005).

It is possible that consideration of the older offender's poor health may be one concern leading to more lenient sentences meted out to them. In fact, older offenders who bring forward appeal cases to have their sentences reduced frequently cite their poor health, together with their advanced age, as a reason for reducing their sentence (Pertierra, 1995). Although the US courts have mostly rejected this argument, stating that age and health are irrelevant factors in sentencing decisions (e.g. Watkins v. State, US v. Guajardo, and People v. Eshelman), a few US jurisdictions accept advanced age (together with youth) as a mitigating circumstance when sentencing (e.g. Alaska, Massachusetts, and Tennessee). However, to date, unlike the research on sentencing and mental illness (Holley, Arboleda Florez, \& Crisanti, 1998; Wear \& Pasewark, 1984), there has been no systematic empirical research on the role of physical health in sentencing. The lack of studies based on archival data or sentencing statistics on this issue may 
be due to the fact that health status is difficult to operationalise and is not routinely recorded in case files or official sentencing statistics. Also the fact that health is viewed as an irrelevant factor for sentencing decisions in many jurisdictions, may have led researchers not to consider it worthy of experimental research.

The Present Research

The main goal of the present research was to measure the age leniency effect in the context of physical health information and relevant legal variables such as offence severity and prior convictions. In recognition of the limitations of archival studies, particularly with regard to the unavailability of health information in publicly available sentencing data, an experimental design was employed.

\section{Experiment 1}

In Experiment 1, we examined the effects of offender age and physical health in the context of offence severity and prior convictions in a case of physical assault. Consistent with the previous findings of an age leniency effect we predicted a main effect for age. We also predicted an interaction of age with health. Specifically, it was predicted that health would be of greater influence on the sentences for older offenders than on those for younger offenders.

Based on prior research (e.g., Steffensmeier et al., 1995), we also hypothesized that legal factors (i.e., offence severity and prior convictions), would be strongly associated with the length of the prison sentence imposed. Although the relative importance of legal and extra-legal factors 
has thus far not been studied within a single experimental study focusing on offender age, we predicted, again based on archival research (Steffensmeier et al., 1995), that the effect sizes for the main effects of the legal factors (offence severity and prior convictions) would be greater than the main effect of age and the interaction effect of age by health.

Finally, we predicted interactions between legal and extra-legal factors. The age leniency effect was predicted to be stronger for the more severe offence than for the less severe offence. The reason for this expectation is that for a longer sentence, which would be likely elicited by a more severe offence, there would be more scope for leniency than for a shorter sentence. Equally, an age leniency effect was predicted to be modified by prior convictions, showing a stronger age leniency effect for those cases in which the offender had a prior conviction. This was assumed because the sentence for those without a prior conviction may already be relatively low, thus leaving less scope for age related leniency.

Method

Participants. The experiment involved 40 student participants recruited from two English universities. Sixteen were men and 24 were women. The mean age of the sample was 24.58 years $(S D=10.00)$.

Design. Offender age, health, previous convictions, and offence severity were manipulated in a 2 (age) x 2 (health) x 2 (prior convictions) x 2 (offence severity) within-subjects factorial design. A within-subjects design increases the power to detect effects and allows for participants to act as their own controls.

The offender's age was varied to be either young (between 21 and 26 years) or old (between 66 and 72 years). Using gerontological terminology, the older offenders were thus all within the category of "young-old" age (65-74 years). Within these age boundaries the precise 
age was allocated randomly in each scenario. The offender's physical health was varied to be either very good or very poor health. Previous convictions had two levels: no previous convictions and one previous conviction for assault causing actual bodily harm. Offence severity had two levels: one less severe, equivalent to actual bodily harm in English Law, and one more severe, equivalent to grievous bodily harm. In the less severe offence condition the offender threw a mug at a neighbor with whom he was having an argument, causing a temporary bruising of his face including a black eye. In the more severe condition, the offender took a kitchen knife in an argument with a neighbor and intentionally cut this neighbor's face, causing scarring and permanent blindness in one eye.

Materials and procedure. The factorial design yielded 16 individual cases. All scenarios involved a physical assault on a neighbour in the offender's kitchen, perpetrated as part of an ongoing dispute. Offender gender and ethnicity were held constant in all cases. An example scenario for the combination of an old offender, poor health, no previous convictions and a severe offence looked like this: “Anthony Rogers is a 68-year-old white male of very poor health. He was convicted of grievous bodily harm for having physically attacked a neighbor. As part of an ongoing dispute about a tree in the garden he and the neighbor had been arguing in Rogers’ kitchen, and he took a kitchen knife and intentionally cut the neighbor's face, causing scarring and permanent blindness in one eye. He has no previous convictions. The maximum penalty for grievous bodily harm is imprisonment for life.”

The cases were collated and presented in a random order. This order varied across participants to minimise order effects, which have been shown for previous within-subjects research on the age leniency effect (Bergeron \& McKelvie, 2004). The cases and questions were pilot tested and the wording of instructions and questions clarified as a result. 
Data was collected in small groups. Each participant received a booklet with instructions and the 16 cases. Participants were asked to imagine that the offender had been found guilty and it was their task to make the sentencing decision. For each case, participants were informed of the maximum sentence that could be imposed according to English Law. This is up to 5 years imprisonment for a conviction of actual bodily harm, and up to life imprisonment for grievous bodily harm. Working individually and anonymously, participants judged in years and months how long a prison sentence for this offender should be. Finally, participants provided demographic information on themselves, such as gender and age. On average, participants took 15 minutes to complete the study.

Results

A repeated measures ANOVA was conducted with length of prison sentence as the dependent variable, and offender's age, health, and previous convictions, and offence severity as the independent variables (repeated measures factors). In order to avoid any problems concerning heterogeneity of variances in the repeated measures ANOVA (Green \& Salkind, 2003) the results of the multivariate tests, rather than the tests of within-subjects effects, are reported here.

As predicted, main effects were observed for age, Hotelling's $t(1,39)=6.98, p=.012$, partial $\eta^{2}=.15$ with a $95 \%$ confidence interval ranging from .01 to .35 , observed power $=.73$, severity of offence, Hotelling's $t(1,39)=32.88, p=.000$, partial $\eta^{2}=.46$ with a $95 \%$ confidence interval ranging from .22 to .61 , observed power $=1.00$, and previous convictions, Hotelling's $t(1,39)=15.72, p=.000$, partial $\eta^{2}=.29$ with a $95 \%$ confidence interval ranging from .07 to .48 , observed power $=.97$. We also observed a main effect for health, Hotelling's $t$ (1, 39) $=6.20, p=.017$, partial $\eta^{2}=.14$ with a $95 \%$ confidence interval ranging from .00 to .33 , 
observed power $=.68$. The predicted interaction of health and age, however, did not emerge, Hotelling's $t(1,39)=.02, p=.886$, observed power $=.05$. Consistent with our hypotheses the effect sizes for legal variables were larger than those for extra-legal variables. There was also the predicted interaction between age and offence severity, Hotelling's $t(1,39)=9.40, p=.004$, partial $\eta^{2}=.19$ with a $95 \%$ confidence interval ranging from .02 to .39 , observed power $=.85$. As Figure 1 shows, longer sentences were imposed for the more severe offence than for the less severe offence, and older offenders tended to receive shorter sentences than younger offenders. However, this difference between the age groups was much greater for the more severe offence (young: $M=75.24$, S.E. $=10.97$; old: $M=59.08$, S.E. $=9.37$ ), than for the less severe offence (young: $M=16.09$, S.E. $=5.26$; old: $M=12.91$, S.E. = 2.82). For the more severe offence, the older offender received on average a sentence that was 16 months shorter than the younger offender. For the less severe offence, the sentence for the older offender was only about 3 months shorter than that of the younger offender. The predicted interaction of age by previous conviction was not observed, Hotelling's $t(1,39)=.40, p=.529$, observed power $=.10$.

\section{INSERT FIGURE 1 ABOUT HERE}

Offenders in poor health received sentences that were on average significantly shorter than offenders in good health $(\mathrm{M}=37.58$ months, $\mathrm{S}$. E. $=5.47$ versus $\mathrm{M}=44.08$ months, $\mathrm{S} . \mathrm{E} .=$ 6.65). Offenders with a previous conviction were sentenced to significantly longer time in prison $(M=45.89$ months, S.E. $=6.78)$ than those without a prior conviction $(M=35.77$, S.E. $=5.30)$. 
In Experiment 1 the effects of offenders' age and health on length of prison sentences for a case of physical assault were investigated in the context of offence severity and previous convictions. The results showed the expected main effects for age, health, severity of offence, and prior convictions.

The effects of both legal variables, previous convictions and offence severity, were consistent with prior archival research, as more severe offences or offenders with previous convictions have been found to receive longer sentences than offenders sentenced for less severe offences or offenders without previous convictions (Steffensmeier et al., 1995). However, as, in accordance with the sentencing law, the stimulus materials listed different maximum sentences for the two different offence severity levels, thus offence severity in this study is confounded with maximum sentence. The different durations of the maximum sentence may have led to anchoring effects in participants' judgments and thus may be partially responsible for the main effect of offence severity.

We also observed the interaction of age by offence severity. Here, the age leniency effect was indeed stronger for the more severe offence than for the less severe offence. We explain this with the assumption of a floor effect for the less severe offence: for the less severe offence the sentence was so short already that there was not much leeway to shorten it noticeably for the older offender. Thus, while an age leniency effect was observed, and older offenders did indeed receive shorter sentences, the age leniency effect was moderated by offence severity. This moderation of the age leniency effect by the legal factor offence severity has so far not been shown. Legal variables and extra-legal variables, so often kept apart in experimental research, interacted. This shows clearly the importance of studying extra-legal factors in the context of legal factors. 
Furthermore, the importance of health information was clearly demonstrated for the length of prison sentence. Offenders in poor health received a sentence that was on average 6.5 months shorter than those of offenders in good health. The impact of physical health has not been shown before in sentencing research. However, we did not observe the expected age by health interaction. We had assumed that health information would mainly affect decisions about older offenders and not be important in sentencing younger offenders. This assumption was not borne out by the data. Health information was as important when sentencing younger offenders as when sentencing older offenders, and so may be worthy of future research on sentencing.

\section{Experiment 2}

In Experiment 2, we aimed to replicate the above findings and examine if the effects of offenders' age and physical health would also be observed for the offence of child sexual abuse ${ }^{1}$. The systematic study of the age leniency effect has been hitherto restricted to violent, property or drugs offences, while sexual offences have not been systematically considered. However, we argue that it is specifically in the context of child sexual abuse that an age leniency effect may be of interest: the prosecution of older men for child sexual abuse is not uncommon. To a considerable extent this may be due to the secrecy that frequently surrounds child sexual abuse, and the reluctance of young victims to come forward. Offences may come to light many years after they occur, and the statute of limitations in many jurisdictions have been loosened or even abolished to make prosecution possible after long delay (Lewis, 2006). Thus, such cases can be brought to court for longer periods than cases for other offences. For this reason, offenders who

\footnotetext{
${ }^{1}$ The specific offence studied in this experiment is "sexual assault of a child under 13 ” as covered by the Sexual Offences Act 2004 S.7 for England and Wales. As much of the psychological literature uses the term child sexual abuse to include this type of offence, we have also adopted this term.
} 
are prosecuted, convicted, and sentenced for child sexual abuse may be considerably older than offenders sentenced for other offences.

In addition there is evidence that even at the time of committing their first offence offenders who engage in child sexual abuse are typically older than offenders who commit other crimes: The average age at first offence of child sexual abuse is in the early to mid-thirties (Greenfeld, 1997). US arrest data shows that while older offenders constitute only a small percentage of arrests for all crimes, the type of crime in which this age group has the greatest representation is sexual offences: offenders over the age of 60 make up only $1.2 \%$ of all arrests for violent offences, $0.9 \%$ of arrests for property offences, and $0.5 \%$ of arrests for drug abuse violations, but 3.8\% of sex offences (excluding forcible rape) (Federal Bureau of Investigation, 2004). (Comparable arrest data with age differentiation over age 60 is not available for the UK.) Incarceration data also supports the view that among older offenders sex offences generally predominate. For instance, in US state prisons, 36.2\% of offenders aged 60 years or above at the time of their arrest were in prison for a charge of sexual assault or rape ${ }^{2}$. Only offenders between the ages of 50 and 59 years had a higher percentage of being imprisoned for a sex offence (45.5\% for the 50-54 year category, 50.6\% for the 55-59 year category) (Greenfeld, 1997). Given that more than a third of offenders aged 60 or above are sent to prison for a sexual crime, studying age leniency effects in the context of sex offences is particularly relevant.

The only study that has any indication of an existence of the age leniency for child sexual offences, is the archival analysis by Wilbanks (1988), which observed a smaller effect for child

\footnotetext{
2 The high percentage of older offenders who are imprisoned for sexual offences as opposed to other offences does not contradict our hypothesis that there may be a leniency effect for sentencing of this age group: Although it shows that for this age group sex offences lead more frequently to imprisonment than other offences, it crucially does not consider older offenders in comparison to younger offenders. Therefore it is impossible to draw any inference from it as to whether sexual offenders over age 60 are sentenced more or less leniently than younger sexual offenders given a comparable offence.
} 
molestation than for the other types of offences studied, e.g. robbery or burglary. However, that study did not focus on child molestation in particular but reported differences in sentence type across a whole range of offences and the only mention of this finding is in a table. Given that Wilbanks’ (1988) study did not control for prior convictions or offence severity, the findings are to be regarded with caution until further research is conducted.

It is however also possible that a simple age leniency effect may not occur for this particular offence or that the effect may be reversed. First, this may be related to possible counter-balancing effects of the "dirty old man” stereotype. This stereotype describes a sexually driven older man who, unable to have sexual relationships with adults, targets children (Walz, 2002). As child sexual abuse is within the realms of expected behaviour within this stereotype, an older sex offender may not benefit from age-related leniency.

Second, an old man who perpetrates a sex crime violates several other stereotypes such as that of the "grandfather figure” (Hummert, 1999), non-threatening figure (Kite \& Wagner, 2002), and that of a person who has ceased to be seen as having sexual motivations (Bouman, Arcelus, \& Benshow, 2006; Praseedom, Tube, Vourdas, Rafnar, \& Woodfield, 1999). Therefore, sentencers may perceive a sexual offence against a child as more "unnatural” and more morally wrong when it is perpetrated by an older offender than when perpetrated by a younger man. Consequently, sentencers may punish the older sex offender more harshly than a younger sex offender. Thus, the literature does not provide unequivocal guidance on whether to expect or not expect an age leniency effect for child sexual abuse.

Given that these two latter possibilities are as yet speculation but that there is the (limited) data by Wilbanks (1988) showing a small age leniency effect, we predicted a main effect of age (with older offenders being sentenced more leniently than younger offenders), albeit 
smaller than was observed for the violent crime in Experiment 1. On the basis of the results obtained in Experiment 1 we also predicted that regardless of age, offenders in poor physical health would be sentenced less severely than offenders in good health. We further hypothesised that sentence length would be longer for the more severe offence than for the less severe offence, and longer for the offence with a prior conviction than for the offence without a prior conviction. Effect sizes were expected to be larger for the legal than for the extra-legal variables. Finally, as in Experiment 1 we predicted interactions of offence severity with age and of prior convictions with age, such that any age leniency effect would be stronger for the more severe offence than for the less severe offence, as well as for the offence with a prior conviction than for the offence without a prior conviction.

\section{Method}

Participants. Forty-seven students from an English university volunteered to participate. There were 36 women and 11 men and their mean age was 22.74 years $(S D=5.37)$.

Design. Offender's age, health, and previous convictions, and offence severity were manipulated in a 2 (age) x 2 (health) x 2 (prior convictions) x 2 (offence severity) within-subjects factorial design. Offender age and health were operationalised as in Experiment 1. Previous convictions had two levels (i.e., no previous convictions and one conviction for a similar sexual offence against a child four years ago). Severity of offence had two levels (i.e., one incident of sexual touching of the genitals over the girl's clothing and repeated touching of the girl's naked genitalia on ten separate occasions over the course of one year). Here, both the frequency as well as the intrusiveness of the offence were varied. Importantly, overcoming the potential confound of offence severity and maximum penalty in Experiment 1, the offence constellation in 
Experiment 2 is one in which both levels of offence severity are subject to the same maximum sentence in English law.

Materials and procedure. The factorial design yielded 16 individual cases. All cases involved a sexual assault of a 7 year-old girl, who was the offender's neighbour's daughter. This victim-perpetrator constellation was chosen because studies of child sexual abuse have shown that for child sexual abuse the offender is frequently acquainted with the victim (Clark \& Mezey, 1997). Participants were asked to imagine that the offender had been found guilty and it was their task to make the sentencing decision. Consistent with the applicable English law, they were also informed that for all cases of sexual assault of a child a judge could "give by law a maximum sentence of 14 years imprisonment or any other sentence less than this.” ${ }^{3}$ The dependent variable was length of prison sentence, measured in years and months. The procedure for data collection was the same as in Experiment 1. On average it took participants 15 minutes to complete the study.

Results

A repeated measures ANOVA was conducted with length of prison sentence as the dependent variable and offenders' age, physical health, and previous convictions, and offence severity as the independent variables (repeated measures factors). The results of the multivariate analysis are reported here.

As expected, main effects were obtained for health, Hotelling's $t(1,46)=12.79, p=.001$, partial $\eta^{2}=.22$ with a $95 \%$ confidence interval ranging from .04 to .40 , observed power $=.94$, for offence severity, Hotelling's $t(1,46)=95.57, p=.000$, partial $\eta^{2}=.68$ with a $95 \%$ confidence interval ranging from .50 to .77 , observed power $=1.00$ and previous convictions,

\footnotetext{
${ }^{3}$ Throughout the materials the cases were referred to only as "sexual assault", and not as "child sexual abuse", in order to avoid confusion of participants.
} 
Hotelling's $t(1,46)=38.79, p=.000$, partial $\eta^{2}=.46$ with a $95 \%$ confidence interval ranging from .24 to .60 , observed power $=1.00$. The predicted main effect of age did not emerge, Hotelling's $t(1,46)=.82, p=.371$, observed power $=.14$. As hypothesised, the main effects of the legal variables were larger than those of the extra-legal variables. None of the predicted 2way interactions of age by offence severity and of age by previous convictions were observed (age by offence severity: Hotelling's $t(1,46)=1.52, p=.224$, observed power $=.23$; age by prior convictions: Hotelling's $t(1,46)=2.07, p=.157$, observed power $=.29)$. However, there was a three-way interaction between age, offence severity and previous convictions, Hotelling's $t$ $(1,46)=5.26, p=.027$, partial $\eta^{2}=.10$ with a 95\% confidence interval ranging from .00 to .28 , observed power $=.15$. Here, for the more severe offence the younger offender received a longer sentence than the older offender and this difference was more pronounced where there had been a previous conviction than when there was no previous conviction. For the less severe offence, the younger offender also received a longer sentence than the older offender if there was no previous conviction. However, if the offender had a previous conviction coupled with the less severe offence, the older offender in fact received a longer sentence than the younger offender (see Table 1, Figure 2). Note, however, that while this three-way interaction was statistically significant, its effect size was small.

Offenders in good health were on average given a significantly longer sentence of 62.90 months $($ S.E. $=5.49)$ compared to offenders in poor health who received on average sentences of 57.92 months (S.E. = 4.97).

INSERT TABLE 1 ABOUT HERE

INSERT FIGURE 2 ABOUT HERE 


\section{Discussion}

Experiment 2 attempted to replicate the findings of Experiment 1 and extend them to the offence of child sexual abuse. The main effect of offenders' physical health was replicated. Offenders in poor health, regardless of age, received on average sentences that were 5 months shorter than those of offenders in good health.

In contrast to the violent crime variation, but consistent with the study by Wilbanks (1988), age of offender was not important as a main effect but only as part of an interaction effect. A three-way interaction effect of age by offence severity by previous convictions was demonstrated. While in general older offenders received shorter sentences than younger offenders regardless of prior conviction for the more severe offence, they received a longer sentence than the younger offender when having committed the less severe offence but having had a prior conviction.

A plausible explanation for this finding may be the fact that this constellation of less severe crime and previous conviction fits well with the “dirty-old man” stereotype. This stereotype includes the image of men who, impotent due to old age, resort to sexual touching or groping of young people, and do so habitually. In our scenario the older offender once touched a girl sexually over her clothing, rather than committing a more intrusive sexual offence. This may be just the type of low level, one-off, touching-only sexual offending expected within this stereotype of older men. It is possible that because of this type of offence, coupled with a previous conviction, the older offender ceases to be perceived as part of the category "old man" (which would merit a more lenient sentence due to old age) and be reassigned to the stereotype category “dirty old man”. The offender, now part of a negatively stereotyped group, would then 
be sentenced more severely. Note however that the effect size for this interaction was quite small and it remains to be seen if this effect can be replicated with other data.

\section{General Discussion}

We investigated the effect of offenders' age and health on sentencing decisions in the context of legal variables (i.e. offence severity and previous convictions). Sentencing was examined for two different offences: a violent assault and child sexual abuse.

For the violent crime, we observed an age leniency effect, moderated by offence severity: Older offenders were sentenced to shorter sentences than younger offenders and the difference in sentence length between the age groups was larger for the more severe offence (grievous bodily harm) than for the less severe offence (actual bodily harm). There was also a main effect of health. Offenders in ill health received on average 6 months shorter sentences than offenders in good health.

For the sexual offence, where overall sentences were 20 months longer than for the violent crime, health had a similar effect. Here, offenders in poor health received sentences that were shorter than those of offenders in good health. No clear age leniency effect was observed for the sexual offence. There was a significant but small interaction effect of age by offence severity by prior convictions.

When an age leniency effect was observed in the present research, it was consistent with previous research. The fact that the age leniency effect was stronger for the violent crime, and precarious for the sexual child abuse scenario is also consistent with previous studies: In the archival literature, the strongest age leniency effect has been found for violent crime (e.g., 
Steffensmeier et al., 1995), while for child molestation the age leniency effect observed was small (Wilbanks, 1988).

For both offence types there were main effects of offence severity and prior convictions, although for the violent crime offence severity was moderated by age, and for the sexual crime both offence severity and previous convictions interacted with age. The importance of these two legal variables observed in this research is consistent with previous findings (Steffensmeier et al., 1995) and consistent with sentencing policy.

In the introduction we had argued that sentencers may treat older offenders more leniently for several reasons. First, older offenders may be generally perceived as being at a lower risk of recidivism and thus pose less risk to the public than do younger offenders. Second, prison sentences may impact more severely on the older offender than his/her younger counterpart which implies that a similar level of retribution may be reached with a shorter sentence for the former group. Our research provides an indication that perhaps old age is used by sentencers as a short-hand for poor health, which is often confounded with old age. If indeed poor health is the underlying consideration of more lenient sentences, the same arguments apply: Individuals in poor health pose a lower risk of reoffending and thus a lower risk to the public, and those who are ill, regardless of age, suffer more from the inability of the prison service to provide the appropriate care. If poor health is really what sentencers have in mind when passing more lenient sentences on older offenders it would be fairer to younger offenders in poor health if health was considered more explicitly.

\section{Strengths and Limitations}

Of course the present two experiments, like other experimental research on sentencing, have their strengths and limitations. Critics may argue that the material for decision making was 
artificial and was not as rich as real cases would be. However, archival data of real sentencing decisions is not available that would allow us to examine the effect of physical health since that information is not routinely recorded. In fact, one strength of the present research over past experimental research is that we included some legally relevant variables.

Another strength of the present research is that it employed a within-subjects design, which compared to the between-subject designs of previous studies has increased power to detect effects. A note of caution however follows from the findings of meta-analytic reviews of the literature on differences in attitudes to younger and older adults, which have shown that withinsubject designs lead on the whole to larger effect sizes than between-subjects designs (Kite \& Johnson, 1988; Kite, Stockdale, Whitley, \& Johnson, 2005). It is therefore possible that any large effect sizes observed in this study are partly due to the choice of design and so may overestimate the real effect size. On the other hand, due to the increased power of the within-subjects design, the two studies also used a small sample size. As apparent in the power analyses the nonsignificant findings showed a lack of power. It is thus possible that these particular nonsignificant findings are due to the sample size, rather than the lack of an observable difference.

Of course within-subjects designs have potential problems such as participant fatigue. In this study we believe that participant fatigue may not have been an issue because the study took on average only 15 minutes to complete. Concerns over practice or other potential order effects were addressed by randomisation of the order of case presentation. The study instructions stressed that participants should work on the cases in the specified order and not refer back or look forward to cases to come (and no such behaviour was observed by the experimenter).

These experiments, like others, used student samples as mock judges rather than obtaining a representative sample of real judges. Although the generalisability of such student- 
based research to the practices of judges is limited, such research can reveal lay peoples’ attitudes towards sentencing. Indeed, sentencing policy has often been guided by public opinion. Finally, although one could study verdicts (rather than sentences) in mock judges, these are problematic as their dichotomous nature makes it difficult to assess the effect of legal and extralegal factors.

Our experimental research is meant as a stepping stone pointing to a promising new area of inquiry. Further research replicating these findings with more representative samples of decision makers is of course needed. In fact, future research could also meaningfully examine the effects of offender age and health on lay peoples' conviction decisions. This could reveal how these extra-legal variables impact pre-sentence decisions.

Overall, the present research makes several contributions. Firstly, on a general level it shows the importance of studying the impact of extra-legal variables on sentencing decisions within the context of legal variables. In future studies, other legally relevant variables could be included in the study of the age leniency effect, such as for instance remorse. Secondly, Experiment 2 focused on the age leniency effect for child sexual abuse. This type of offence had so far not been systematically examined in the context of the age leniency effect. Age leniency seems to play a very minor role in this type of crime, moderated by offence severity and previous convictions. Thirdly, the use of two very different offences - a violent crime and a sexual crimeshowed that the age leniency effect is not a universal phenomenon. Even where it occurred, i.e. for the violent offence, it was moderated by offence severity.

Finally, poor health emerged as a variable that showed a leniency effect across the two different offence types and independent of age as well as the legal variables. As older offenders are more likely to be in poor health than younger offenders it is possible that what has been 
interpreted as an age leniency effect in archival studies, may in fact be due in part to an unrecognised health leniency effect. Of course, given that health information is not routinely recorded, it would be impossible to disentangle the effects of age and health in existing archival data. Given the difficulties the prison service has in accommodating chronically ill and frail prisoners, and the resulting harsher consequences of imprisonment for offenders in poor health when compared with offenders in good health, it is plausible that health of offender should be taken into account when sentencing. Physical health therefore seems a promising addition to the canon of extra-legal variables studied in research on sentencing decisions. 


\section{References}

Aday, R. (2006). Managing the special needs of ageing prisoners in the United States. In A. Wahidin \& M. Cain (Eds.), Ageing, Crime and Society (pp. 210-229). Cullompton: Willan.

Aday, R. H. (2003). Aging prisoners. Westport, Connecticut: Praeger.

Ashworth. (2005). Sentencing and criminal justice (4th ed.). Cambridge: Cambridge University Press.

Bergeron, C. E., \& McKelvie, S. J. (2004). Effects of defendant age on severity of punishment for different crimes. Journal of Social Psychology, 144(1), 75-90.

Bouman, W. P., Arcelus, J., \& Benshow, S. M. (2006). Nottingham Study of Sexuality \& Ageing (NoSSA I). Attitudes regarding sexuality and older people: A review of the literature. Sexual and Relationship Therapy, 21(2), 149-161.

Bushway, S. D., \& Piehl, A. M. (2007). The inextricable link between age and criminal history in sentencing. Crime and Delinquency, 53(1), 153-183.

Champion, D. (1987). Elderly felons and sentencing severity: Intergenerational variations in leniency and sentencing trends. Criminal Justice Review, 12, 7-14.

Champion, D. (1988). The severity of sentencing: Do federal judges really go easier on elderly felons in plea bargaining negotiations compared with their young counterparts? In B. McCarthy (Ed.), Older Offenders: Perspectives on Criminology and Criminal Justice (pp. 143156). New York: Praeger.

Clark, C., \& Mezey, G. (1997). Elderly sex offenders against children: a descriptive study of child sex abusers over the age of 65. The Journal of Forensic Psychiatry, 8(2), 357-369.

Dhami, M. K. (2007). Sentencing decisions. In B. Cutler (Ed.), Encyclopaedia of Law and Psychology. Sage. 
Farrington, D. P. (1986). Age and crime. In M. Tonry \& N. Morris (Eds.), Crime and Justice: An Annual Review of the Research (Vol. 7, pp. 189-250). Chicago: University of Chicago Press.

Federal Bureau of Investigation. (2004). Crime in the United States 2003 - Uniform Crime Reports.Washington, D.C.: US Government Printing Office.

Green, S. B., \& Salkind, N. J. (2003). Using SPSS for Windows and Macintosh.Upper Saddle River, N.J.: Prentice Hall.

Greenfeld, L. A. (1997). Sex offenses and offenders - An analysis of data on rape and sexual assault (No. NCJ-163392). Washington DC: U.S. Department of Justice.

Higgins, P. L., Heath, W. P., \& Grannemann, B. D. (2007). How type of excuse defense, mock juror age, and defendant age affect mock jurors' decisions. Journal of Social Psychology, 147(4), 371-392.

Holley, H., Arboleda Florez, J., \& Crisanti, A. (1998). Do forensic offenders receive hasher sentences? An examination of legal outcomes. International Journal of Law and Psychiatry, 21(1), 43-57.

Hummert, M. L. (1999). A social cognitive perspective on age stereotypes. In F. Blanchard-Fields \& T. M. Hess (Eds.), Social Cognition and Aging (pp. 175-196). San Diego, CA: Academic Press.

Johnston, C. W., \& Alozie, N. O. (2001). The effect of age on criminal processing: Is there an advantage in being "older"? Journal of Gerontological Social Work, 34(4), 65-82.

Kapardis, A., \& Farrington, D. P. (1981). An experimental study of sentencing by magistrates. Law and Human Behaviour, 5(2/3), 107-121. 
Kerbs, J. J. (2000). The older prisoner: Social, psychological, and medical considerations. In M. B. Rothman, B. D. Dunlop \& P. Entzel (Eds.), Elders, Crime, and the Criminal Justice System (pp. 207-228). New York: Springer.

Kite, M. E., \& Johnson, B. T. (1988). Attitudes toward older and younger adults: a metaanalysis. Psychology and Aging, 3(3), 233-244.

Kite, M. E., Stockdale, G. D., Whitley, B. E. J., \& Johnson, B. T. (2005). Attitudes toward younger and older adults: an updated meta-analytic review. Journal of Social Issues, 61(2), 241-266.

Kite, M. E., \& Wagner, L. S. (2002). Attitudes towards older adults. In T. D. Nelson (Ed.), Ageism: Stereotyping and Prejudice against older persons. Cambridge, MA: MIT Press. Lewis, P. (2006). The delayed prosecution for childhood sexual abuse.Oxford: Oxford University Press.

Loeffler, R., \& Lawson, T. J. (2002). Age and occupational status of defendant in relation to mock juror sentencing recommendation. Current Psychology: Developmental, Learning, Personality, Social, 21(3), 289-292.

McKelvie, S. J., \& Bergeron, C. E. (2003). Defendants' age and severity of punishment for two crimes in a mock scenario: further data. Perceptual and Motor Skills, 97, 621-624.

Pertierra, C. J. (1995). Do the crime, do the time: Should elderly criminals receive proportionate sentences? Nova Law Review, 19(2), 791-819.

Praseedom, A., Tube, P. A., Vourdas, A., Rafnar, B., \& Woodfield, M. (1999). Stereotypes of ageing. British Journal of Psychiatry, 175, 190. 
Silverman, M., Smith, L. G., Nelson, C., \& Kosberg, J. (1984). The perception of the elderly criminal when compared to adult and juvenile offenders. In W. Wilbanks \& P. Kim (Eds.), Elderly Criminals. Lanham, New York, London: University Press of America.

Steffensmeier, D., Kramer, J., \& Ulmer, J. (1995). Age differences in sentencing. Justice Quarterly, 12(3), 583-601.

Steffensmeier, D., \& Motivans, M. (2000). Older men and older women in the arms of criminal law: Offending patterns and sentencing outcomes. Journal of Gerontology: Social Sciences, 55B(3), 141-151.

Steffensmeier, D., Ulmer, J., \& Kramer, J. (1998). The interaction of race, gender, and age in criminal sentencing: the punishment cost of being young, black, and male. Criminology, 36(4), 763-793.

Turner, G. S., \& Champion, D. J. (1989). The elderly offender and sentencing leniency. Journal of Offender Counseling, Services, Rehabilitation, 13(2), 125-140.

Von Hirsch, A., \& Ashworth, A. (Eds.). (1998) Principled sentencing. Second edition. Oxford: Hart.

Walz, T. (2002). Crones, dirty old men, sexy seniors: Representations of the sexuality of older persons. Journal of Aging and Identity, 7(2), 99-112.

Wear, D. A., \& Pasewark, R. A. (1984). Defendants previous history and mock sentencing. Journal of Clinical Psychology, 40(3), 867-874.

Wilbanks, W. (1988). Are elderly felons treated more leniently by the criminal justice system? International Journal of Aging, 26, 275-288. 


\section{Legal Cases Cited}

People v. Eshelman, 275 Cal. Rptr. 810 (2d Dist. Ct. App. 1990).

United States v. Guajardo, 950 F. 2d 203 (5 ${ }^{\text {th }}$ Cir. 1991) cert. Denied, 112 S. Ct. 1773 (1992).

Watkins v. State, 225 S.E.2d. at 739 (1976). 
Table 1. Means and standard deviations for the length of prison sentence imposed by age, offence severity and previous convictions for Experiment 2 (sexual offence)

\begin{tabular}{|c|c|c|c|c|c|}
\hline \multirow[t]{2}{*}{ Age } & \multirow{2}{*}{$\begin{array}{l}\text { Offence } \\
\text { severity }\end{array}$} & \multicolumn{2}{|c|}{ No Prior conviction } & \multicolumn{2}{|c|}{ One prior conviction } \\
\hline & & $\mathrm{M}$ & SD & $\mathrm{M}$ & SD \\
\hline \multirow[t]{2}{*}{ Young } & Low & 33.65 & 4.66 & 43.53 & 4.98 \\
\hline & High & 79.91 & 6.29 & 86.86 & 6.89 \\
\hline \multirow[t]{2}{*}{ Old } & Low & 29.54 & 4.00 & 47.83 & 5.97 \\
\hline & High & 78.64 & 6.59 & 83.31 & 6.79 \\
\hline
\end{tabular}




\section{Figure Captions}

Figure 1. Mean length of prison sentence by age and offence severity in Experiment 1 (violent offence), including standard errors.

Figure $2 a$ and $b$. Mean length of prison sentence by offender age, offence severity and prior conviction in Experiment 2 (sexual offence), including standard errors. 
Effects of Offenders' Age and Health 35

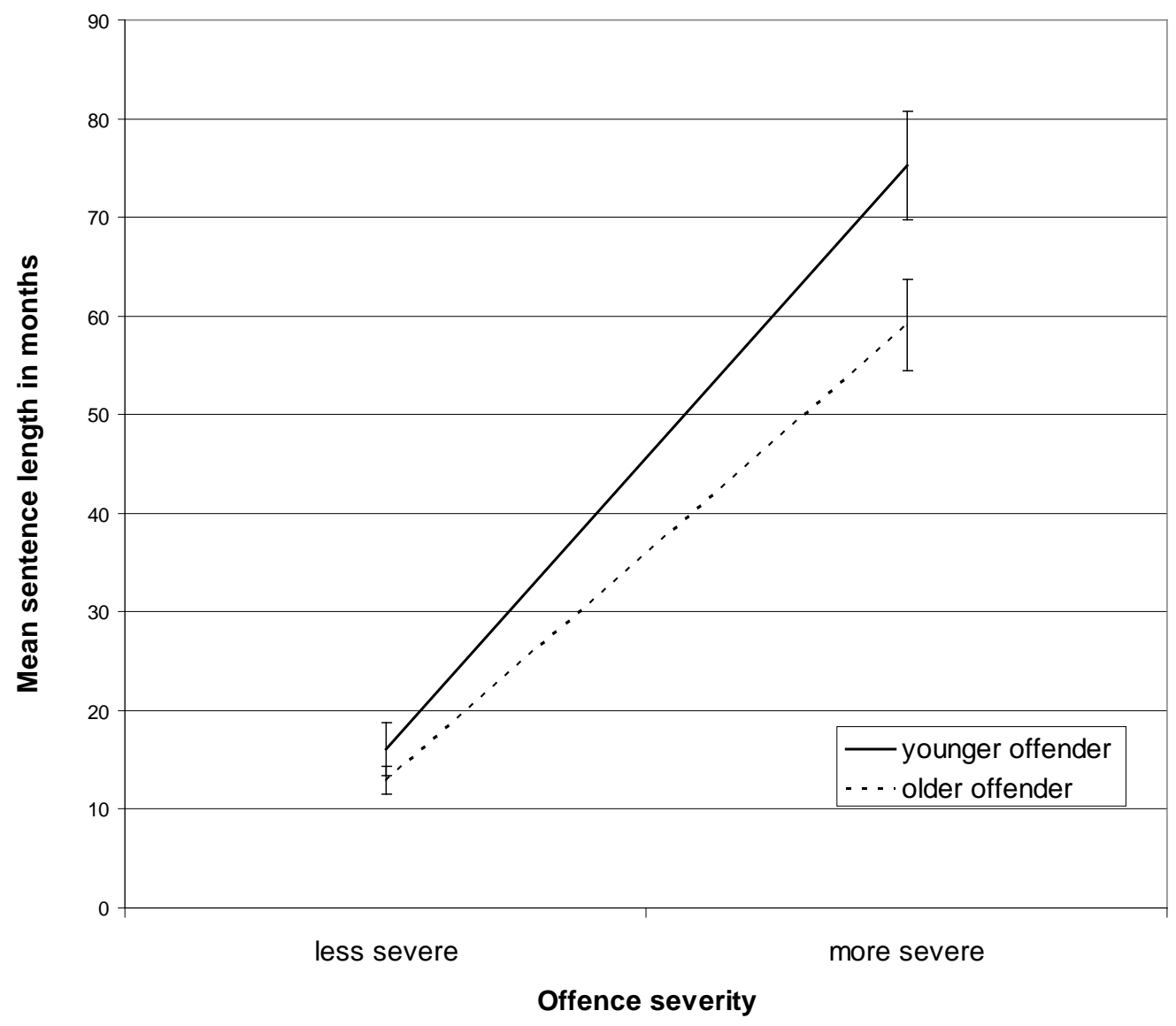




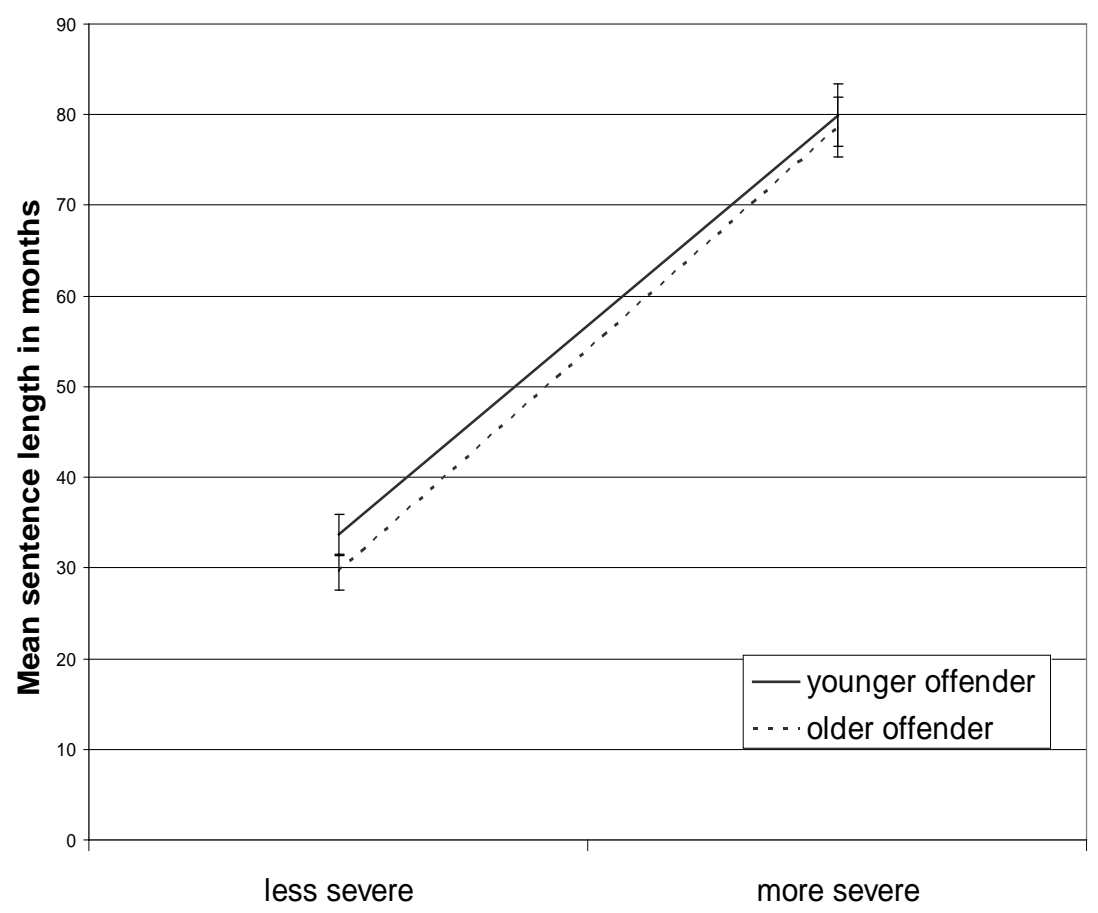

Offence severity

No previous conviction

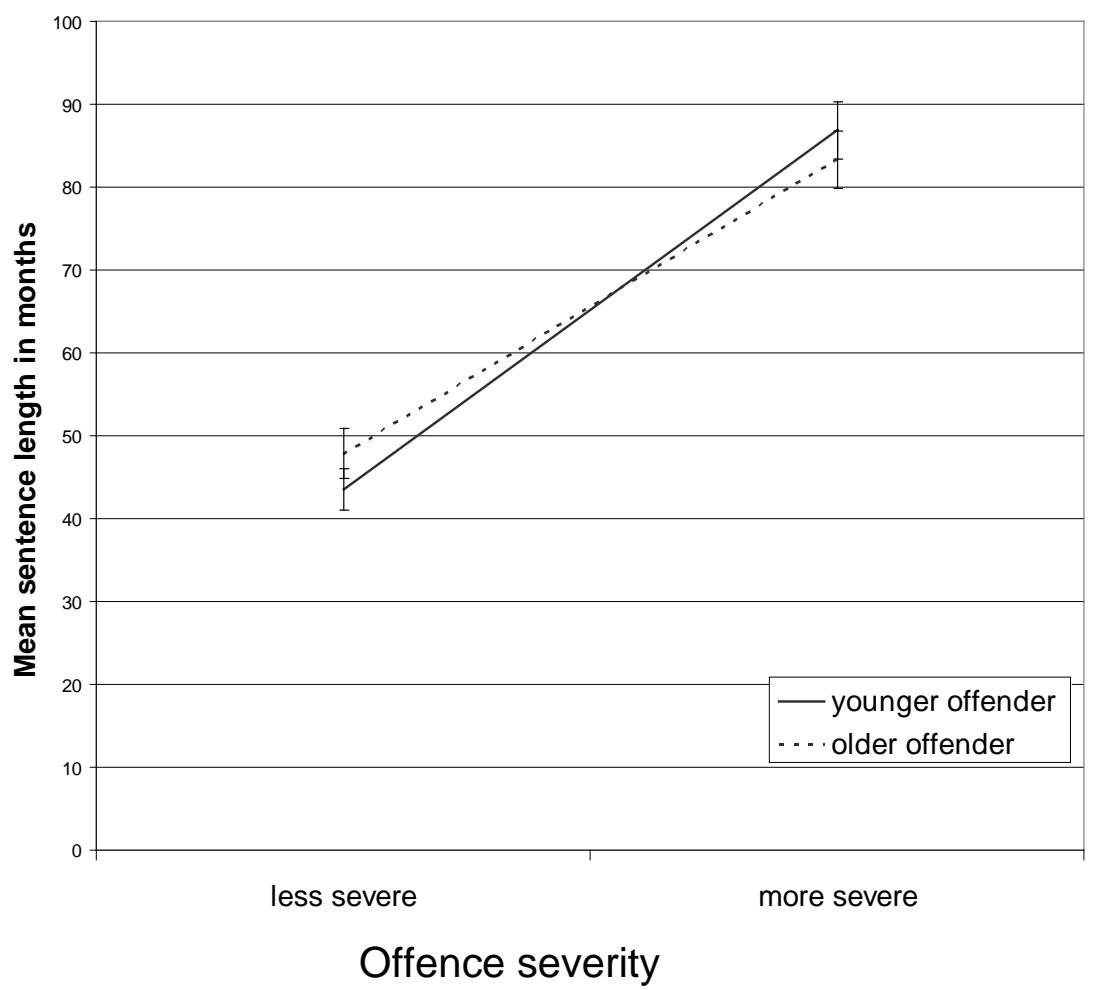

One previous conviction 